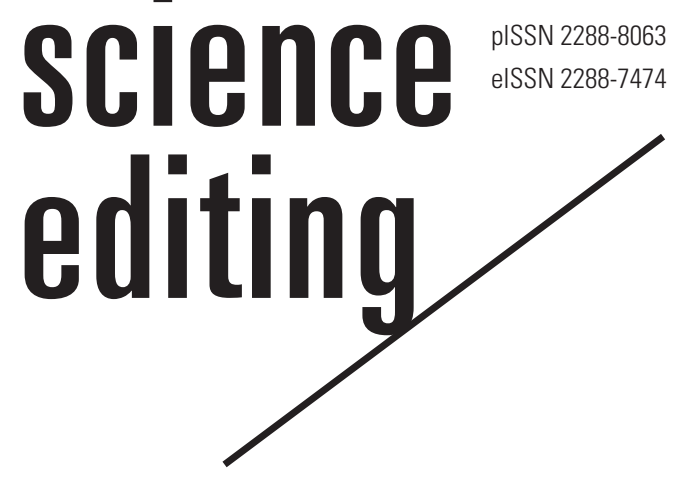

\title{
Five clusters of flood management articles in Scopus from 2000 to 2019 using social network analysis
}

\author{
Rosy Riani Kusuma ${ }^{1,2}$ Ida Widianingsih', Sinta Ningrum', Rita Myrna' \\ ${ }^{1}$ Faculty of Social and Political Sciences, Universitas Padjadjaran, Bandung; ${ }^{2}$ Badan Pengawasan Keuangan dan \\ Pembangunan, Jakarta, Indonesia
}

\section{Abstract}

Purpose: This study aimed to analyze the bibliographic characteristics and content of articles on flood management published in journals indexed by Scopus written by researchers from throughout the world from 2000 to 2019.

Methods: We obtained data from the Scopus database on October 2, 2020. "Flood management" was used to search across several categories, including article title, abstract, and keywords, filtered by subject area (social science; environmental science; and business, management, and accounting). We only retrieved articles written in English. We conducted content analysis using the VOSviewer software and visualized the co-occurrence of keywords and bibliographic coupling of sources and countries.

Results: Following the study protocol, we found 984 articles on flood management over the past 20 years. Among the three subject areas, environmental science was the most productive field for publishing flood management articles. Flood control, flood management, and risk assessment were the top three most popular topics. Flood management publications were published in 266 journals. In total, 86 countries collaborated to produce research related to flood management. Natural Hazard Journal and Journal of Flood Risk Management were the most prominent journals. Institutions from Europe ominated the top 10 institutions with the most publications by af-

Received: October 13, 2020

Accepted: November 15, 2020

Correspondence to Rosy Riani Kusuma rosy18002@mail.unpad.ac.id

ORCID

Rosy Riani Kusuma

https://orcid.org/0000-0003-2519-4174

Ida Widianingsih

https://orcid.org/0000-0003-2472-5236

Sinta Ningrum

https://orcid.org/0000-0002-5934-9851

Rita Myrna

https://orcid.org/0000-0002-9437-8818 filiated researchers.

Conclusion: From a global perspective, flood management research in the past two decades has increased significantly. There were five major topic clusters, and European-published journals ominated publications. Thus, Asian institutions need to conduct more active research on this topic.

Keywords

Bibliometric; Flood management; Publications; Scopus; VOSviewer 


\section{Introduction}

Background/rationale: Researchers have found that the frequency of flood occurrences worldwide is closely related to climate change [1-3]. Developing countries are considered to be the most vulnerable areas to flooding due to the multiple economic, social, and environmental impacts of floods [4]. Asia is the continent that recorded the most frequent disasters [5], and in Africa, 64\% of disasters that occurred over the last two decades (2000-2019) were catastrophic floods. Similar events have also occurred in Europe [6]. The economic loss caused by floods in India and the United States (2018-2019), for example, amounted to 10 billion US dollars each. Similarly, flooding in Jakarta, Indonesia, in 2007 caused financial losses of 5.2 trillion Indonesian rupiah [7]. Meanwhile, in Venezuela, floods in 1999 were estimated to have claimed 30,000 people's lives and damaged settlements and other infrastructure [8]. Although some researchers have produced bibliometric articles on flooding occurrence and flood management [9-11], we have not found any bibliometric articles that utilized social network analysis.

Objectives: This aim of this article was to provide useful data for understanding global publication trends regarding flood management. This study aimed to analyze the bibliographic characteristics and trends of articles on flood management published in journals indexed in Scopus written by researchers from throughout the world from 2000 to 2019 and to conduct an analysis of keyword co-occurrence using VOSviewer.

\section{Methods}

Ethics statement: This study did not deal with human subjects: therefore, neither approval by the institutional review board nor informed consent was required.

Study design: This was a literature database-based descriptive study.

Data sources: We used the Scopus database as the primary source for information, since Scopus is considered to be a reliable source by academics. We used the term "flood management" as a specific parameter in the article search. The selection of keywords in Scopus involved not only flood management, but also other keywords that appeared frequently along with flood management. For example, flood management often co-occurred with the concept words "resilience, "hazard," and "uncertainty" [12].

Analysis methods: Next, we followed the methods presented in an earlier paper on social network analysis for the scientific literature on low-carbon supply chain management because we were not able to find a bibliometric study using social network analysis with topics related to flood management [13].
In the first phase, we browsed the Scopus database on October 2, 2020. We searched for all articles published in the Scopus database using "flood management" as a keyword, and then sorted the data based on title, abstract, and keyword in the search tab. We also limited the searching criteria by only including articles published in the last 20 years (2000-2019). We additionally limited our search to articles, and chose "all" for the access type. In this step, we found 1,364 publications. Next, we refined the results by applying an inclusion strategy to limit the number of articles by using three subject areas (including social science; environmental science; and business, management, and accounting). We also narrowed the search by applying certain filters to other parameters, such as "final" articles for publication stage, "journal" for the source type, and only articles in the English language. In this inclusion stage, we retrieved 984 publications.

In the next step, we downloaded the articles from the Scopus database and analyzed the 984 publications that had been sorted by relevance.

Visualization: Our third stage was analyzing the collected articles using VOSviewer ver. 1.6.15 (https://www.vosviewer. $\mathrm{com} /$ ) for data interpretation. The first VOSviewer analysis used was co-occurrence to identify themes in flood management. We selected the "all keyword" option to ensure that all of the keywords in the publications would be retrieved. In the next step, we presented trends in flood management publications, and then we conducted a co-occurrence analysis using VOSviewer and bibliographic coupling for sources and countries. Based on this step, we presented the top 10 significant journals and the top 10 countries with the most affiliations.

\section{Results}

Amount of flood management research from 2000 to 2019 The amount of flood management publications in three subject areas (social science; environmental science; and business, management, and accounting) over the past 20 years globally showed a positive trend (Fig. 1). However, there were some fluctuations over the years in the annual number of publications related to flood management in the Scopus database. Environmental science was the subject area with the most publications related to flood management, with 867 publications, followed by social science with 288 , and business, management, and accounting with 25 articles. However, the number of publications related to flood management in the business, management and accounting subject area was relatively limited, with only a single article published before 2007 and only five documents related to flood management published in 2019. 


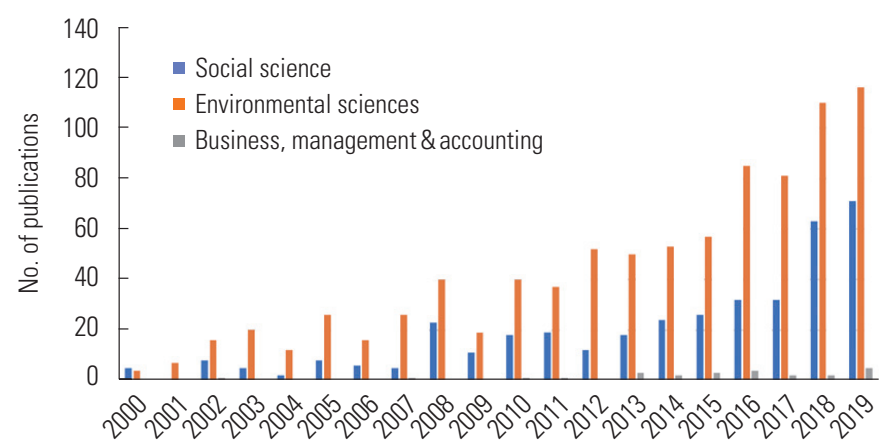

Fig. 1. Trends in flood management publications from 2000 to 2019 in the Scopus database.

Content analysis of flood management publications

A content analysis was performed of the 984 publications sorted by relevance. Next, we performed a co-occurrence analysis with VOSviewer, using the "all keyword" analysis unit and the "full counting" method. We limited the frequency of keyword occurrence to 10 times; out of 6,086 keywords, VOSviewer found 269 keywords that met the threshold. The results of this analysis are presented in Fig. 2.

Flood control (588), flood management (284), and risk assessment (247) were the top three keywords that appeared most frequently. Moreover, we found five clusters in this analysis. The first cluster, represented in red, consisted of 90 keyword items with the keyword "flood control" being the most common, as marked by a larger size than the other nodes. The keywords "hydrological modeling" (90), "rainfall-runoff modeling" (39), "flood forecasting" (9), and "watershed" (51) were the most widely featured discussion topics in international articles discussing flood management in the subject areas of social science; environmental science; and business, management, and accounting. The geographic regions that appeared in this first cluster included China, Iran, and Malaysia. Thus, based on the 90 keywords in cluster 1, this cluster appears to be a series of articles discussing flood control and flood modeling in Asian countries.

The second cluster (green) consisted of 83 keywords, among which "flood management" (284), "risk assessment" (247), "hazard management" (110), "disaster management" (97), and "climate change" (148) were the most commonly used. The keyword "flood risk management" (90) was connected to "adaptive management" (62) and "governance approach" (36). However, the distance from flood management was further than for other keywords in the same cluster, indicating that the relationship was not yet strong. Furthermore, the keywords "environmental policy" (19), "Asia" (16), "policy implementation" (11), and "local government" (10) had smaller nodes and were located in the outermost position rel-

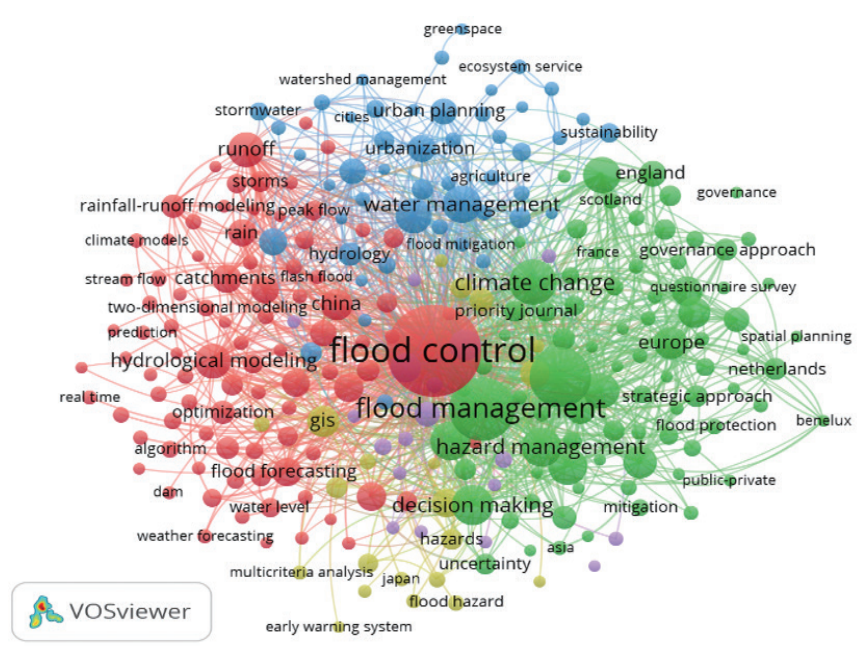

Fig. 2. Network visualization of flood management articles published globally in the Scopus database from 2000 to 2019.

ative to other keywords, indicating that publications on this topic are still limited in number. This cluster's geographical regions were European and Asian countries. It can be inferred that the articles in this cluster mostly discussed flood risk management in Europe and Asia, and started to build connections with the governance approach and adaptive management.

The third cluster, represented in blue, consisted of 48 keywords, of which "water management" (100), "urban area" (86), "sustainable development" (82), "urbanization" (52), and "urban planning" (49) appeared most widely. India, Indonesia, and Australia appeared in cluster 3 The third cluster mostly dealt with water management and its connection with urban development. In comparison, the fourth cluster (yellow) consisted of 21 keywords, among which "GIS" (70) (which had a connection with the first cluster [flood modeling and forecasting] and the third cluster [urban floods]), "hazard assessment" (58), and "integrated approach" (40) were widely encountered. Interestingly, there were "flood risk" keywords connected closely to the "risk assessment" keyword in the second cluster. Furthermore, "early warning system" and "multicriteria analysis" were located at the outermost point of cluster 4. Japan and Thailand were the countries that tended to appear in this cluster. Nevertheless, the fourth cluster raised discussions about the analyses and approaches used for hazard assessment

Finally, the fifth cluster, which is represented in purple, consisted of 18 keywords. This cluster connected the keywords "floodplain" (71) with "flood control" in the first cluster and "flood management" in the second cluster. This cluster also connected the keywords "environmental risk" (14) with "risk assessment." The United States, Canada, and California ap- 


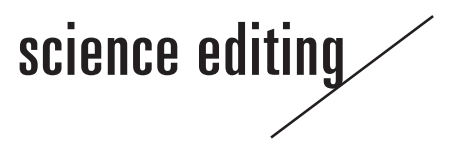

peared most frequently in this cluster. as some of the articles in the fifth cluster dealt with the risk of flooding in the United States and Canada.

Fig. 3 shows an overlay visualization of the flood management literature with the average number of publications from 2011 to 2016. There was a shift in topics; around 2013, the literature on flood management contained extensive discussions of the terms "disaster management," "mitigation," and "Europe," which then developed into "flood management" and "flood control," and then the last 3 years discussed "risk assessment" and "risk management." The latest articles on flood management also discussed the governance approach, since in the last 3 years, the keywords "adaptive governance," "government approach," and "environmental risk" have appeared. However, the distance between nodes was longer than for other themes, indicating that these thematic relationships were weaker than those for different themes. This analysis also showed that flood control has been connected to the literature on governance, albeit to a limited extent.

The density visualization analysis showed that research with keywords related to public administration such as "governance approach," "local government," "policy approach," and "policy implementation" had relatively limited impact. Although it appeared in clusters, these studies were not widely associated with other studies, as seen in Fig. 4. Thus, research on flood management in the future can raise further issues related to governance, policy implementation, and local government.

Bibliographic coupling of sources on flood management in social science; environmental science; and business, management, and accounting

We restricted the article search by selecting only the areas of social science; environmental science; and business, management, and accounting and retrieved 984 publications. We

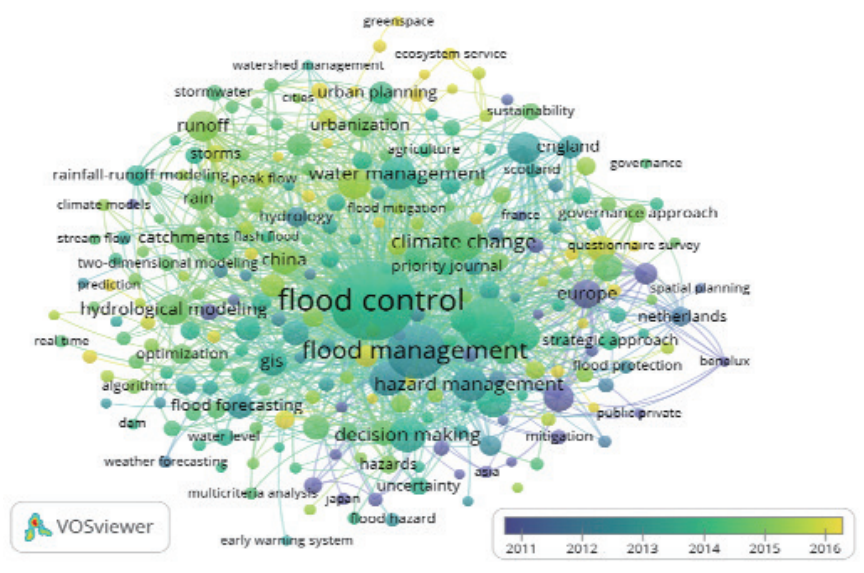

Fig. 3. Overlay visualization of global flood management articles. sorted the articles based on their relevance. Over the past two decades, Natural Hazard Journal (Netherlands) published the most articles containing "flood management" in their titles/ keywords and abstracts, with 60 articles. The second-ranked journal was the Journal of Flood Risk Management (Denmark). The top 10 journals that published articles related to flood management are presented in Table 1 . There were four journals each from the United Kingdom and the Netherlands, and one journal each from Denmark and Switzerland.

Bibliographic coupling of sources with at least five documents and one minimum citation resulted in 266 sources, of which 48 met the threshold. Based on network visualization

Table 1. Top 10 journals on flood management in the subject areas of social science, environmental science, and business, management, and accounting

\begin{tabular}{clcc}
\hline Rank & \multicolumn{1}{c}{ Journal } & $\begin{array}{c}\text { No. of } \\
\text { publications }\end{array}$ & Country \\
\hline 1 & Natural Hazards & 60 & Netherlands \\
2 & Journal of Flood Risk Management & 46 & Denmark \\
3 & Water Switzerland & 37 & Switzerland \\
4 & Journal of Hydrology & 36 & Netherlands \\
5 & Water Resources Management & 35 & Netherlands \\
6 & International Journal of River Basin & 25 & United Kingdom \\
& Management & & \\
7 & Environmental Science and Policy & 22 & Netherlands \\
8 & Wit Transactions on Ecology and the & 22 & United Kingdom \\
$\quad$ Environment & & \\
9 & International Journal of Water & 21 & United Kingdom \\
$\quad$ Resources Development & & \\
10 & Water International & 18 & United Kingdom \\
\hline
\end{tabular}

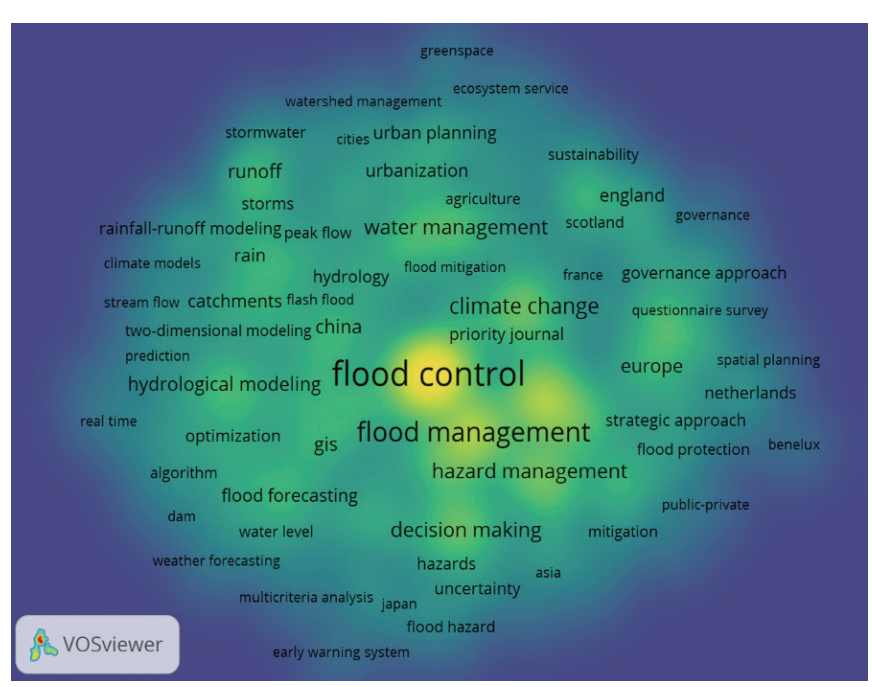

Fig. 4. Density visualization of flood management articles from global scholars. 
as seen in Fig. 5, there were five journal clusters. The top three journals were in a single cluster of three (blue). Cluster 1 consisted of journals with a hydrology scope, and cluster 2 was dominated by environmental journals. The third cluster contained journals dealing with natural hazard and flood management.

Interestingly, cluster 4 had quite a dispersed network compared to other clusters, indicating that this cluster did not have many citations in common with other clusters. The fourth cluster consisted of the Journal of Canadian Water Resources, Disaster Prevention and Management, and Environmental Hazards. Furthermore, the fifth cluster consisted of only one journal, Environmental Engineering, which was connected to the third cluster.

From the overlay visualization, it was seen that the most recent discussions on flood management in the last 2 years were published in Water (Switzerland), Sustainability (Switzerland), and Modeling Earth Systems and Env (Fig. 6).

Table 2 presents the top five journals with flood management publications from the three subject areas. The Journal of Flood

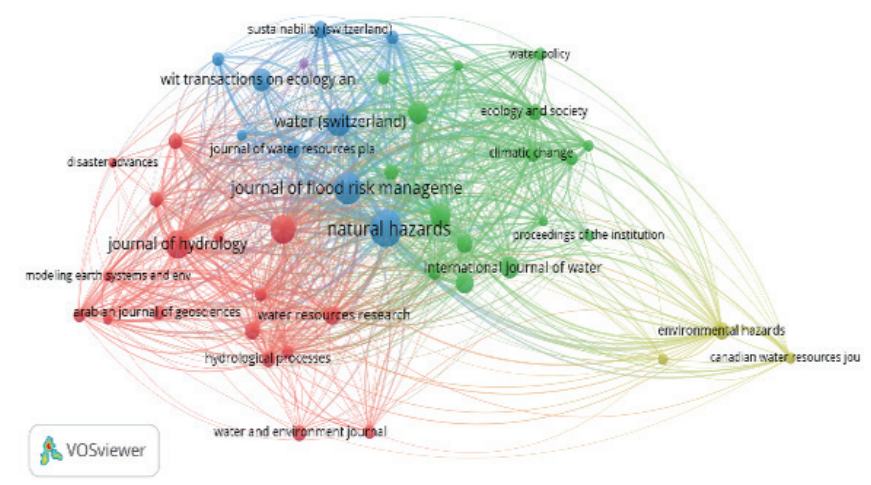

Fig. 5. Network visualization of bibliographic coupling of sources on flood management.

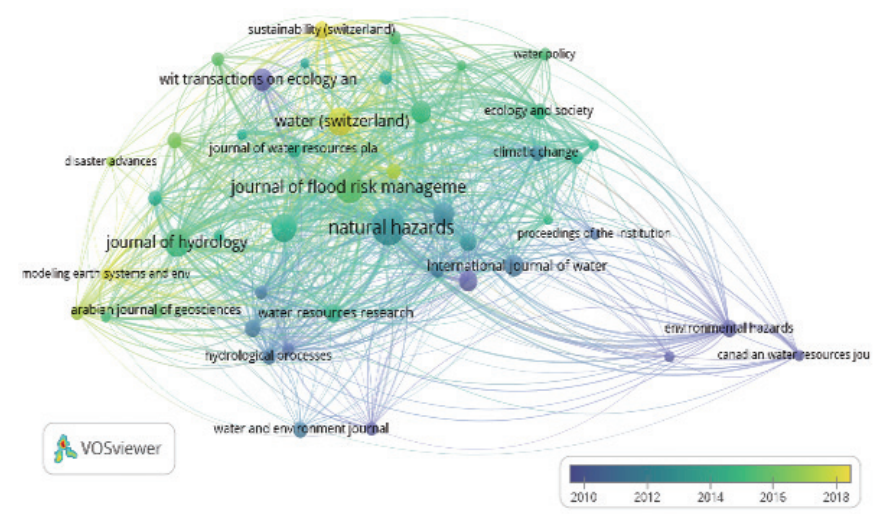

Fig. 6. Overlay visualitation of bibliographic coupling of sources on flood management.

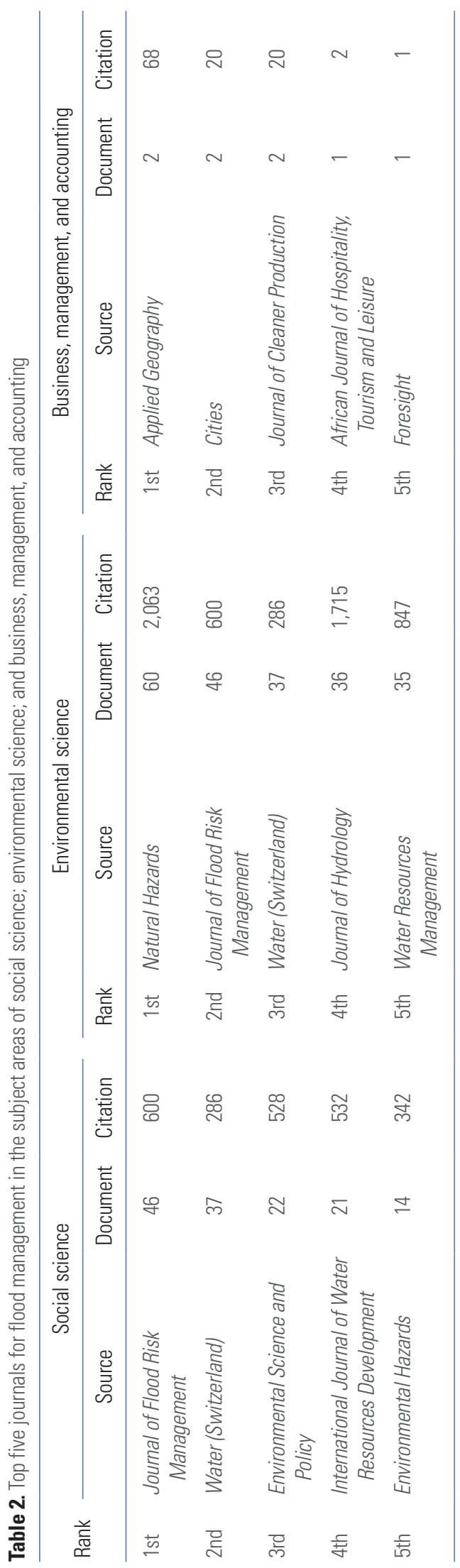




\section{science editing /}

Risk Management and Water (Switzerland) are both renowned journals in social science and environmental science.

Bibliographic coupling of countries for research on flood management in the areas of social science; environmental science; and business, management, and accounting

In the period 2000 to 2019, the United Kingdom was the country with the most publications on flood management, with 205 articles, followed by the United States with 151 articles. China, Japan, India, and Iran were the Asian countries ranked in the top 10 countries in terms of the most flood management publications in the areas of social science; environmental science; and business, management, and accounting. These four Asian countries ranked fourth, eighth, ninth, and tenth, respectively. The top 10 countries can be seen in Fig. 7 below.

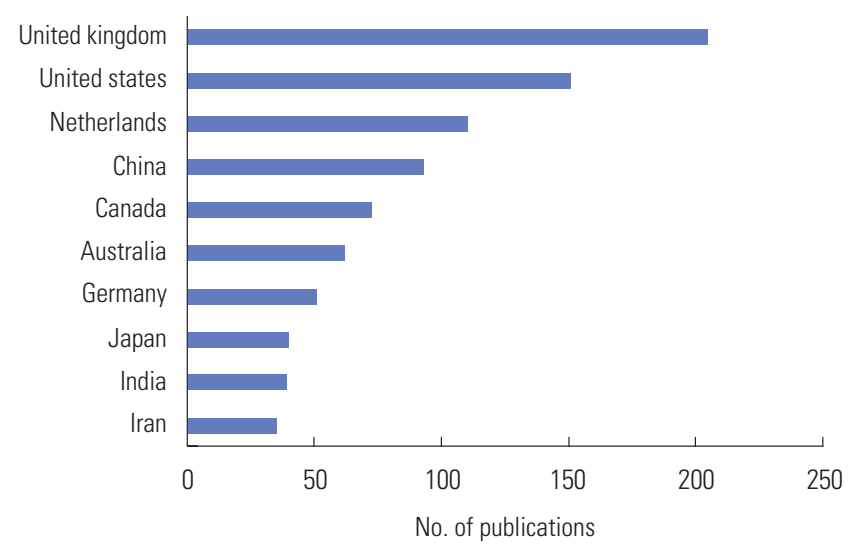

Fig. 7. Top 10 countries with publications on flood management.

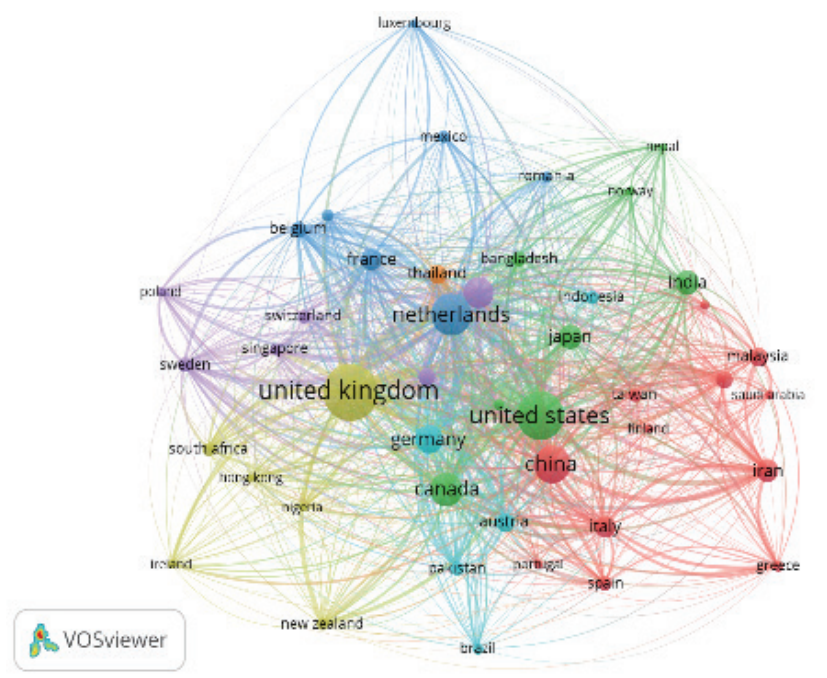

Fig. 8. Network visualization of bibliographic coupling of countries for flood management research.
An analysis of bibliographic coupling of countries with at least five documents and one citation resulted in 86 countries, of which 45 met the threshold. Based on the network visualization as seen in Fig. 8, there were seven clusters. A larger circle for a given node indicates that a country is more productive. The United Kingdom, United States, Netherlands, and China were in different clusters. Some of the countries that collaborated with researchers in the United Kingdom were New Zealand, South Africa, Nigeria, and Ireland, while the United States showed connections to Canada, Japan, and Indonesia. Interestingly Thailand was the only country in cluster 7, but had proximity to the Netherlands in cluster 3 and Australia in cluster 5. Meanwhile, the overlay visualization showed that researchers from developing countries primarily began publishing flood management articles in the last 5 years, as shown in Fig. 9.

\section{Affiliations with global institutions}

In the last 20 years, the IHE Delft Institute for Water Education was the institution with the most flood managementthemed publications, with 30 articles, followed by the Delft University of Technology (with 27 articles) and Wageningen University \& Research (with 21 articles). Four each of the top 10 institutions were in the Netherlands and the United Kingdom, as seen in Table 3. The Chinese Academy of Sciences was the only Asian institution among the top 10 institutions that published flood management publication in the subject areas of social science; environmental science; and business, management, and accounting.

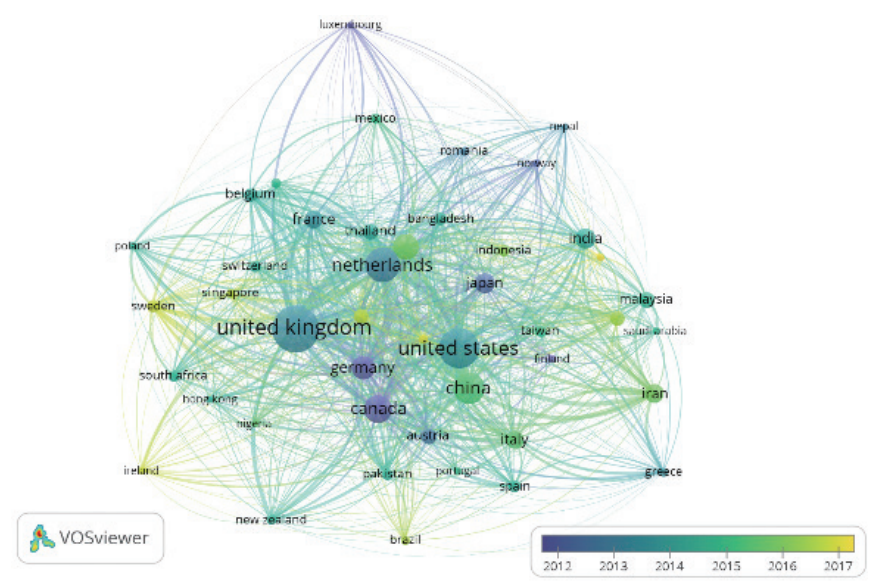

Fig. 9. Overlay visualization of bibliographic coupling of countries for flood management research. 
Table 3. Top 10 institutions in terms of affiliation

\begin{tabular}{clcc}
\hline No. & \multicolumn{1}{c}{ Institution } & Document & Country \\
\hline 1 & IHE Delft Institute for Water Education & 30 & Netherlands \\
2 & Delft University of Technology & 27 & Netherlands \\
3 & Wageningen University \& Research & 21 & Netherlands \\
4 & Chinese Academy of Sciences & 19 & China \\
5 & Newcastle University & 18 & United Kingdom \\
6 & University of Leeds & 17 & United Kingdom \\
7 & University of Exeter & 17 & United Kingdom \\
8 & University of Dundee & 16 & United Kingdom \\
9 & Western University & 16 & Canada \\
10 & Vrije Universiteit Amsterdam & 13 & Netherlands \\
\hline
\end{tabular}

\section{Discussion}

Interpretation: Based on data from Scopus, the publication trends, journal performance, content analysis, and bibliographic coupling of countries and sources were analyzed for research on flood management issues throughout the world. The results showed that worldwide scientific publications on flood management grew significantly. Of the three subject areas that were analyzed, environmental science was the most productive field for flood management publications. The global content analysis yielded five clusters with five critical topics: flood modeling, flood risk management, watershed and river management, approaches/analyses of flood hazards, and environmental risk. However, limited research from a global perspective on flood management in the past 3 years has discussed flood management and its relationship with governance within the scope of social science and environmental science.

Journals from Europe published the most flood management-related articles. The Journal of Flood Risk Management and Water are renowned in the areas of social science and environmental science, and published numerous publications on flood management. The United States, United Kingdom, and Netherlands were the most productive countries in terms of flood management articles. However, in the last 5 years, researchers in developing countries began doing research and publishing flood management articles in these three subject areas. Although institutions from Europe dominated the top 10 institutions with the most publications by affiliated researchers, the Chinese Academy of Sciences is the only institution from Asia in the top five.

Limitation: We recognize that this study is not free of limitations for several reasons. First, we only retrieved studies from Scopus and did not use other sources such as Web of Science,
Crossref, or PubMed Central. Secondly, we only analyzed three subject areas. Finally, we did not use other analyses in VOSviewer, such as co-citation or co-authorship. Thus, we hope that bibliometric research on this topic will expand in terms of the databases used, the subject areas, and the analyses conducted in order to provide a broader overview of the issue.

Conclusion: In the past two decades, global research on flood management has increased significantly. Previous studies on flood management have focused on technical and disaster management issues, but have paid little attention to public administration. The theme of research on flood management related to environmental policy, policy implementation, and local government could be interesting for future discussions. There are also opportunities to foster discussions about flood management in social science journals related to public administration. Finally, Europe dominated this field in terms of publications and affiliations, while research from Asia on this topic remains limited, and further research is therefore necessary.

\section{Conflict of interest}

No potential conflict of interest relevant to this article was reported.

\section{Funding}

This article received support from Indonesia Endowment Fund for Education (LPDP).

\section{Data Availability}

Dataset file is available from: the Harvard Dataverse at: https:// doi.org/10.7910/DVN/NUHJF7.

Dataset 1. Scopus database on flood management retrieved on October 2 , 2020

\section{References}

1. Hirabayashi Y, Mahendran R, Koirala S, et al. Global flood risk under climate change. Nat Clim Chang 2013;3:81621. https://doi.org/10.1038/nclimate1911

2. Hammond MJ, Chen AS, Djordjevic S, Butler D, Mark O. Urban flood impact assessment: a state-of-the-art review. Urban Water J 2015;12:14-29. https://doi.org/10.1080/157 3062X.2013.857421

3. Al-Amin AQ, Nagy GJ, Masud MM, Filho WL, Doberstein B. Evaluating the impacts of climate disasters and the integration 
of adaptive flood risk management. Int J Disaster Risk Reduct 2019;39:101241. https://doi.org/10.1016/j.ijdrr.2019.101241

4. Palinkas LA. Fleeing flooding: Asia and the Pacific. In: Palinkas LA. Global climate change, population displacement, and public health [Internet]. Cham: Springer; 2020 [cited 2020 Dec 20]. Available from: https://doi.org/10.1007/9783-030-41890-8_6

5. Centre for Research on the Epidemiology of Disasters. Natural disasters 2019 [Internet]. Brussels: EM-DAT; 2020 [cited 2020 Dec 20]. Available from: https://reliefweb.int/sites/reliefweb. int/files/resources/ND19.pdf

6. Raadgever T, Sweco, De Bilt TN, Hegger D, editors. Flood risk management strategies and governance [Internet]. Cham: Springer; 2018 [cited 2020 Dec 20]. Available from: https://doi.org/10.1007/978-3-319-67699-9

7. Nasional BAPPENAS. Damage and loss assessment report in Jabodetabek area caused by the early 2007 flood [Internet]. Jakarta: Ministry of National Development Planning; 2007 [cited 2020 Dec 20]. Available from: https://www.bappenas. go.id/files/8913/5441/6576/hasil-penilaian-kerusakan-dankerugian-pasca-bencana-banjir-awal-februari-2007-di-wilayahjabodetabek_20081123211335_1300_0.pdf

8. Takahashi T, Nakagawa H, Satofuka Y, Kawaike K. Flood and sediment disasters triggered by 1999 Rainfall in Vene- zuela: a river restoration plan for an alluvial fan. J Nat Disaster Sci 2001;23:65-82. https://ci.nii.ac.jp/naid/110002663734

9. Emmer A. GLOFs in the WOS: bibliometrics, geographies and global trends of research on glacial lake outburst floods (Web of Science, 1979-2016). Nat Hazards Earth Syst Sci 2018;18:813-27. https://doi.org/10.5194/nhess-18-813-2018

10. Gao C, Ruan T. Bibliometric analysis of global research progress on coastal flooding 1995-2016. Chin Geogr Sci 2018;28: 998-1008. https://doi.org/10.1007/s11769-018-0996-9

11. Rehman S, Sahana M, Hong H, Sajjad H, Ahmed BB. A systematic review on approaches and methods used for flood vulnerability assessment: framework for future research. Nat Hazards 2019;96:975-98. https://doi.org/10.1007/s1 1069-01803567-z

12. Bruijn KM, Green C, Johnson CD, McFadden L. Evolving concepts in flood risk management: searching for a common language. In: Begum S, Stive MJ, Hall JW, editors. Flood risk management in Europe. Dordrecht: Springer; 2007. p. 61-75.

13. Shaharudin MS, Fernando Y, Chiappetta Jabbour CJ, Sroufe R, Jasmi MF. Past, present, and future low carbon supply chain management: a content review using social network analysis. J Clean Prod 2019;218:629-43. https://doi.org/10.1016/ j.jclepro.2019.02.016 